Correction

\title{
Correction: Xu, C., et al. Effects of Artificial LED Light on the Growth of Three Submerged Macrophyte Species during the Low-Growth Winter Season: Implications for Macrophyte Restoration in Small Eutrophic Lakes. Water 2019, 11, 1512
}

Chao Xu ${ }^{1,2}$, Hai-Jun Wang ${ }^{1, *}$, Qing Yu ${ }^{1,2}$, Hong-Zhu Wang ${ }^{1}$, Xiao-Min Liang ${ }^{1}$, Miao Liu ${ }^{1,2}$ and Erik Jeppesen ${ }^{3,4}$ (D)

1 State Key Laboratory of Freshwater Ecology and Biotechnology, Institute of Hydrobiology, Chinese Academy of Sciences, Wuhan 430072, China; xuchao3091@live.com (C.X.); yuqzoe@163.com (Q.Y.); wanghz@ihb.ac.cn (H.-Z.W.); liangxm@ihb.ac.cn (X.-M.L.); 15827478943@163.com (M.L.)

2 University of Chinese Academy of Sciences, Beijing 100049, China

3 Department of Bioscience and Arctic Research Centre, Aarhus University, 8600 Silkeborg, Denmark; ej@bios.au.dk

4 Sino-Danish Centre for Education and Research, Beijing 100049, China

* Correspondence: wanghj@ihb.ac.cn; Tel.: +86-27-6878-0225; Fax: +86-27-6878-0064

Received: 26 December 2019; Accepted: 26 December 2019; Published: 14 February 2020

The authors wish to make the following corrections to this paper [1]:

We would like to change the authors' institution from:

University of Chinese Academy of Science, Beijing 100049, China.

to the correct version, as follows:

University of Chinese Academy of Sciences, Beijing 100049, China.

The authors would like to apologize for any inconvenience caused to the readers by this change.

\section{Reference}

1. Xu, C.; Wang, H.-J.; Yu, Q.; Wang, H.-Z.; Liang, X.-M.; Liu, M.; Jeppesen, E. Effects of Artificial LED Light on the Growth of Three Submerged Macrophyte Species during the Low-Growth Winter Season: Implications for Macrophyte Restoration in Small Eutrophic Lakes. Water 2019, 11, 1512. [CrossRef]

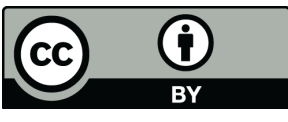

(C) 2020 by the authors. Licensee MDPI, Basel, Switzerland. This article is an open access article distributed under the terms and conditions of the Creative Commons Attribution (CC BY) license (http://creativecommons.org/licenses/by/4.0/). 